\title{
Construction and sorption properties of pyrene-based porous aromatic frameworks
}

Zhuojun Yan, ${ }^{a}$ Hao Ren,${ }^{a}$ Heping Ma, ${ }^{a}$ Rongrong Yuan,,${ }^{a}$ Ye Yuan, ${ }^{a}$ Xiaoqin Zou, ${ }^{a}$ Fuxing $\operatorname{Sun}^{a}$ and Guangshan Zhu*a,b

${ }^{a}$ State Key Laboratory of Inorganic Synthesis and Preparative Chemistry, College of Chemistry, Jilin University, Changchun, 130012, China.

Fax: +86 431 85168331; Tel: +86 431 85168331; E-mail: zhugs@ jlu.edu.cn

${ }^{\mathrm{b}}$ Queensland Micro- and Nanotechnology Centre, Griffith University, Queensland, 4111, Australia. 


\begin{abstract}
We report here pyrene-based fluorescent porous aromatic frameworks (PAF-19 and PAF-20), which are constructed by a quadrilateral building unit 1,3,6,8-tetrabromopyrene (TBrPy) with linkers 1,4-diethynylbenzene and 1,3,5-triethynylbenzene via Sonogashira-Hagihara coupling reaction, respectively. TG analysis shows that PAF-19 and PAF-20 are thermally stable up to $350^{\circ} \mathrm{C}$ in air condition. Both materials also exhibit high chemical stability and cannot dissolve or decompose in any common organic solvents. $\mathrm{N}_{2}$ sorption results reveal that the BET surface areas of PAF-19 and PAF-20 are $250 \mathrm{~m}^{2} \mathrm{~g}^{-1}$ and $702 \mathrm{~m}^{2} \mathrm{~g}^{-1}$, respectively. They also display relatively high sorption abilities for hydrogen and carbon dioxide. $\mathrm{H}_{2} \mathrm{O}$ sorption measurements demonstrate that the skeletons of PAF-19 and PAF-20 are highly hydrophobic. Interestingly, PAF-19 and PAF-20 exhibit excellent sorption abilities to organic chemical pollutants at the saturated vapor pressure and room temperature. PAF-20 can adsorb large amounts of methanol and benzene, with values of $609 \mathrm{mg} \mathrm{g}^{-1}$ and $1038 \mathrm{mg} \mathrm{g}^{-1}$, respectively. The good performances of PAF-19 and PAF-20 with high sorption selectivity promise their potential application for eliminating environmental pollutants in presence of $\mathrm{H}_{2} \mathrm{O}$.
\end{abstract}

\title{
Keywords
}

Porous aromatic frameworks; Sonogashira-Hagihara coupling reaction; Hydrophobic materials; Selective sorption. 


\section{Introduction}

In recent years, many advances have been made in the design and synthesis of porous organic frameworks (POFs) with good mechanical stability, high surface area, controlled surface functionality, and their wide applications in fields of gas storage, molecular separation and catalysis, etc. [1-3] POFs prepared by elaborative selection of building blocks and connection via robust covalent bonds, have been classified according to different types of chemical reactions, such as base-mediated aromatic nucleophilic substitution reaction [4-9], imide formation reaction [10-15], Pd-mediated Sonogashira-Hagihara coupling reaction [16-22], Pd-mediated Suzuki coupling reaction [23-27], $\mathrm{Ni}(\operatorname{cod})_{2}$-mediated Yamamoto coupling reaction [28-33], $\mathrm{ZnCl}_{2}$ mediated nitrile cyclotrimerization reaction [34-39], borate ester formation reaction [40-43], borate anhydride formation reaction [44-47], $\mathrm{FeCl}_{3}$-mediated thiophenyl-thiophenyl oxidative coupling reaction [48,49], lithium-mediated element-carbon bond formation reaction [50,51], etc. The excellent performances of POFs make themselves appropriate as gas storage media, such as $\mathrm{H}_{2}$ and $\mathrm{CH}_{4}$ storage and $\mathrm{CO}_{2}$ capture, which are current concerns in clean energy and environment issues [52,62]. Organic chemical pollutants in air as grievous environmental problem have received unprecedented public attention. Porous materials, such as zeolites, activated carbons and inorganic-organic hybrids, have shown their abilities to deal with organic pollutants in some extent [53-56]. However, their further application has been limited by lower adsorption capacity, broad pore size distribution or low chemical stability in comparison with some reported POFs. Very recently, we have successfully synthesized a series of porous aromatic frameworks (PAFs) [26,33], revealing high adsorption capacities for organic chemical molecules such as benzene, methanol and toluene due to their aromatic networks. In this paper, we report the synthesis and characterizations of two pyrene-based fluorescent PAF materials, PAF-19 and PAF-20. As illustrated in Fig. 1, PAF-19 and PAF-20 are constructed by a quadrilateral building unit 1,3,6,8-tetrabromopyrene (TBrPy) with a linear linker 1,4-diethynylbenzene and a triangular linker 1,3,5-triethynylbenzene via Sonogashira-Hagihara coupling reaction, respectively. PAF-19 and PAF-20 with plentiful phenyl rings in networks exhibit permanent porosity, high thermal and chemical stabilities, and excellent sorption abilities towards organic chemical pollutants at the saturated vapor pressure and room temperature.

\section{Experimental}




\subsection{Materials}

1,3,5-Triethynylbenzene, tetrakis(triphenylphosphine)palladium and copper(I) iodide were received from Alfa Aesar. 1,4-Diethynylbenzene was received from Tokyo Kasei (TCI, 98\%). $N, N$-Dimethylformamide (DMF) and triethylamine $\left(\mathrm{Et}_{3} \mathrm{~N}\right)$ were dried with $\mathrm{CaH}_{2}$ prior to use. Other chemicals and solvents were purchased from commercial suppliers and used as received. TBrPy was prepared according to a previously reported literature [57].

\subsection{Synthesis of PAF-19 and PAF-20}

In the synthesis of PAF-19, TBrPy (0.5 mmol, $259 \mathrm{mg}), 1,4$-diethynylbenzene (1.5 mmol, $189 \mathrm{mg})$, tetrakis(triphenyl-phosphine)palladium (30 mg) and copper(I) iodide (10 mg) were added to a round-bottomed flask. Anhydrous DMF $(5 \mathrm{~mL})$ and $\mathrm{Et}_{3} \mathrm{~N}(5 \mathrm{~mL})$ were added through a syringe. The reaction mixture was heated to $80{ }^{\circ} \mathrm{C}$ under $\mathrm{N}_{2}$ atmosphere for $72 \mathrm{~h}$. After cooling to room temperature, the crude product was filtered and washed with chloroform, methanol, and acetone to remove any unreacted monomers or catalyst residues. Further purification of the polymers was carried out by Soxhlet extraction with tetrahydrofuran for $48 \mathrm{~h}$. The product was dried in vacuum for $24 \mathrm{~h}$ at $60{ }^{\circ} \mathrm{C}$ to give PAF-19 (197 mg). PAF-20 was synthesized using the similar procedure with a replacement of 1,4-diethynylbenzene by 1,3,5-triethynylbenzene (1.0 mmol, $150 \mathrm{mg}$ ). Around $188 \mathrm{mg}$ of the final PAF-20 product was obtained after washing and drying.

\subsection{Characterizations}

The FTIR spectra were collected on an IFS 66V/S Fourier transform infrared spectrometer using $\mathrm{KBr}$ pellets. The thermalgravimetric analysis (TGA) was performed using a TA model TGA Q500 thermal analyzer system up to $800{ }^{\circ} \mathrm{C}$ under air atmosphere at a heating rate of $5{ }^{\circ} \mathrm{C} \mathrm{min}^{-1}$. Solid-state ${ }^{13} \mathrm{C}$ CP/MAS NMR measurement was carried out on a Bruker Avance III model 400 MHz NMR spectrometer at a MAS rate of $5 \mathrm{kHz}$. The SEM pictures were taken on a JEOL model JSM-6700F scanning electron microscope and Iridium (IXRF Systems) software with an accelerating voltage of $5 \mathrm{kV}$. High resolution transmission electron microscopy (HRTEM) was performed on a JEOL JEM 3010 with an acceleration voltage of $300 \mathrm{kV}$. PXRD was performed by a Riguku D/MAX2550 diffractometer using $\mathrm{Cu}-\mathrm{K} \alpha$ radiation, $40 \mathrm{kV}, 200 \mathrm{~mA}$ with a $2 \theta$ range of $4^{\circ}-40^{\circ} . \mathrm{N}_{2}$ and $\mathrm{H}_{2}$ adsorption isotherms were measured on Quantachrome model Autosorb-1C analyzer. $\mathrm{CO}_{2}$ and organic molecules sorption isotherms were measured using Autosorb $\mathrm{iQ}_{2}$ (Quantachrome) adsorption analyzer. 


\section{Results and Discussion}

\subsection{Structure Characterizations}

\subsubsection{FTIR spectroscopy}

The structures of PAF-19 and PAF-20 are firstly studied by FTIR spectroscopy. Fig. 2 shows IR spectra of initial monomers and final products. By comparison, it can be found that the characteristic absorption peak for $\mathrm{C}-\mathrm{Br}$ at $495 \mathrm{~cm}^{-1}$ disappears, which gives an indication for the breakage of the $\mathrm{C}-\mathrm{Br}$ bonds of $\mathrm{TBrPy}$. In addition, the intense absorption peak associated with alkynyl C-H stretching vibration near $3300 \mathrm{~cm}^{-1}$ from the terminal alkyne groups vanishes. Meanwhile, a peak with low intensity is observed near $2200 \mathrm{~cm}^{-1}$ in the final product, which is assigned to the alkyne $-\mathrm{C} \equiv \mathrm{C}$ - stretching vibration mode. The evidences in the IR results prove that the PAF-19 and PAF-20 are formed by the cross-coupling reaction.

\subsection{2. ${ }^{13} \mathrm{C}$ CP/MAS NMR}

To further reveal the local structures of PAF-19 and PAF-20 networks, solid-state ${ }^{13} \mathrm{C}$ CP/MAS NMR was performed. As shown in Fig. S1, all of the carbon signals with a chemical shift in the range of $120-140 \mathrm{ppm}$ are observed, which are related to aromatic carbon atoms of building phenylene groups in the framework. Additionally, the structures with triple-bond linkages have been confirmed by the characteristic resonance of a triple-bonded carbon with a corresponding peak at around $90 \mathrm{ppm}$. The results of ${ }^{13} \mathrm{C} \mathrm{CP} / \mathrm{MAS}$ NMR suggest that this cross-coupling reaction is effective in the synthesis of conjugated organic polymers.

\subsubsection{Powder X-ray diffraction}

Powder X-ray diffraction (PXRD) was used to investigate the crystallinity of PAF-19 and PAF-20 samples (Fig. S2). It indicates that their textures are amorphous. The long-range disorder of structures could be due to the twisting between pyrene units and linkers in the networks (Fig. S3) $[58,59]$.

\subsubsection{Scanning electron microscopy and Transmission electron microscopy}

Scanning electron microscopy (SEM) images (Fig. S4) show that PAF-19 and PAF-20 afforded a spherical morphology with $50-100 \mathrm{~nm}$ in size. High resolution transmission electron microscopy (HRTEM) images (Fig. 3) also indicate that the textures of PAF-19 and PAF-20 are amorphous but with uniform pores.

\subsection{Physicochemical Properties}




\subsubsection{Optical properties}

As clearly seen, the colors of PAF-19 and PAF-20 powders are red and yellow, respectively (Fig. S5). Further, UV-Visible spectra (Fig. S6) were collected on PAF-19, PAF-20 and TBrPy monomer. As shown in Fig. S6, both PAF-19 and PAF-20 samples show broad absorptions in the spectra, indicating their high conjugated nature. Meanwhile, the photoluminescent properties of PAF-19 and PAF-20 were also investigated using fluorescence spectroscopy by dispersing their solid samples in ethanol solvent $(1.5 \mathrm{mg} / 10 \mathrm{ml})$ at room temperature (Fig. S7). The photoluminescent spectrum of PAF-19 (Fig. S7a) shows a strong emission band centered at $639 \mathrm{~nm}$, and the spectrum of PAF-20 (Fig. S7b) shows a broad emission profile with three main peaks centered at 543,585 and $623 \mathrm{~nm}$, respectively. These observations are consistent with UV data.

\subsubsection{Stability of PAF-19 and PAF-20}

The thermal and chemical stabilities of PAF-19 and PAF-20 were investigated. As displayed in thermogravimetric analysis (TGA) curve (Fig. 4), PAF-19 and PAF-20 decompose up to $350{ }^{\circ} \mathrm{C}$ in air condition, indicating they possess high thermal stability. The chemical stability was tested by additional experiments using organic solvents (e.g. THF, acetone, ethanol, DMF, DMSO, etc.) and aqueous solution of acids and bases $(1 \mathrm{M} \mathrm{HCl}$ and $1 \mathrm{M} \mathrm{NaOH})$. It has been found that both solids cannot dissolve or decompose in these common solvents and solutions, indicating their high chemical stability.

\subsection{3. $\mathrm{N}_{2}$ sorption measurements}

To characterize the porosities of the PAF-19 and PAF-20 networks, the nitrogen sorption isotherms were measured on the activated samples at $77 \mathrm{~K}$ from 0 to 1 bar. As shown in Fig. 5a, the $\mathrm{N}_{2}$ sorption isotherm of PAF-19 displays a typical microporous feature of a high uptake at the low relative pressure, followed by a steady increase at the high relative pressure. Similarly, an analogous isotherm is observed in PAF-20 sample (Fig. 5b). To be mentioned, PAF-20 exhibits an exceptionally high $\mathrm{N}_{2}$ uptake of $1215 \mathrm{~cm}^{3} \cdot \mathrm{g}^{-1}$ at $\mathrm{P} / \mathrm{P}_{0}=0.99$. When the Brunauer-Emmett-Teller (BET) model is adopted to calculate the apparent surface area, the surface areas of PAF-19 and PAF-20 are $250 \mathrm{~m}^{2} \cdot \mathrm{g}^{-1}$ and $702 \mathrm{~m}^{2} \cdot \mathrm{g}^{-1}$, respectively. Although the surface areas are not very high among reported POFs, these values still exceed some well-studied micro- and mesoporous materials $[60,61]$. Derived from appropriate non-local density functional theory (NL-DFT) model, PAF-19 and PAF-20 exhibit narrow pore-size distributions with mean pore sizes of $1.33 \mathrm{~nm}$ and 
$1.38 \mathrm{~nm}$, respectively. Estimated from the amount of gas uptake at $\mathrm{P} / \mathrm{P}_{0}=0.99$ (Fig. S8), the total pore volume is $0.43 \mathrm{~cm}^{3} \mathrm{~g}^{-1}$ and $1.88 \mathrm{~cm}^{3} \mathrm{~g}^{-1}$ for PAF-19 and PAF-20 respectively, while the cumulative pore volume derived from NL-DFT is $0.28 \mathrm{~cm}^{3} \mathrm{~g}^{-1}$ (PAF-19) and $1.45 \mathrm{~cm}^{3} \mathrm{~g}^{-1}$ (PAF-20).

\subsection{Sorption properties of PAF-19 and PAF-20}

\subsection{1. $\mathrm{H}_{2}$ sorption}

As well known, the porous materials are good candidates for gas sorption or storage. Based on the consideration of clean energy and environment issues, the gas sorption capacities of PAF-19 and PAF-20 are exemplified by hydrogen and carbon dioxide gases. As shown in Fig. 6a, at 1 bar, the $\mathrm{H}_{2}$ uptake of PAF-19 is $62 \mathrm{~cm}^{3} \cdot \mathrm{g}^{-1}$ at $77 \mathrm{~K}$ and $52 \mathrm{~cm}^{3} \cdot \mathrm{g}^{-1}$ at $87 \mathrm{~K}$, respectively. In the case of PAF-20 (Fig. 6a), at 1 bar, the $\mathrm{H}_{2}$ uptake is $100 \mathrm{~cm}^{3} \cdot \mathrm{g}^{-1}$ at $77 \mathrm{~K}$ and $59 \mathrm{~cm}^{3} \cdot \mathrm{g}^{-1}$ at $87 \mathrm{~K}$, respectively. The $\mathrm{H}_{2}$ uptakes of PAF-19 and PAF-20 are comparatively lower than other POFs, but the plentiful phenyl rings in the PAF networks could lead to an enhancement for the adsorption enthalpies of $\mathrm{H}_{2}\left(\mathrm{Q}_{\mathrm{stH} 2}\right)$. Fig. $6 \mathrm{~b}$ shows that PAF-19 and PAF-20 materials have $\mathrm{Q}_{\mathrm{st}}$ values of 6.99 $\mathrm{kJ} \cdot \mathrm{mol}^{-1}$ and $8.07 \mathrm{~kJ} \cdot \mathrm{mol}^{-1}$ at zero loading, respectively (Details of $\mathrm{Q}_{\mathrm{st}}$ calculation in Supporting Information, Fig. S9 and S10). From the $\mathrm{Q}_{\mathrm{stH} 2}$ list of similar materials in Table 1, the $\mathrm{Q}_{\mathrm{stH} 2}$ of PAF-20 is higher than most of POFs, with an exception of CMP-0-5 $\left(\sim 10 \mathrm{~kJ}^{\left.-\mathrm{mol}^{-1}\right)}\right.$ [21]. Inspired by this experimental result, more efforts are still underway for the successful design of novel PAF materials with high $\mathrm{Q}_{\mathrm{stH} 2}$.

\subsection{2. $\mathrm{CO}_{2}$ sorption}

Encouraged by the high $\mathrm{Q}_{\mathrm{stH} 2}$ of PAF-19 and PAF-20, we have an enthusiasm to investigate the $\mathrm{Q}_{\mathrm{stCO} 2}$ of PAF-19 and PAF-20. As shown in Fig. 7a, at 1 bar, the volumetric $\mathrm{CO}_{2}$ uptake of PAF-19 is $20.1 \mathrm{~cm}^{3} \cdot \mathrm{g}^{-1}$ at $273 \mathrm{~K}$ and $13.3 \mathrm{~cm}^{3} \cdot \mathrm{g}^{-1}$ at $298 \mathrm{~K}$, respectively. For the PAF-20 sample (Fig. 7a), at $1 \mathrm{bar}$, the $\mathrm{CO}_{2}$ uptake is $25.9 \mathrm{~cm}^{3} \cdot \mathrm{g}^{-1}$ at $273 \mathrm{~K}$ and $14.7 \mathrm{~cm}^{3} \cdot \mathrm{g}^{-1}$ at $298 \mathrm{~K}$, respectively. From the adsorption isotherms of $\mathrm{CO}_{2}$ at $273 \mathrm{~K}$ and $298 \mathrm{~K}$ (Fig. S11 and S12), the $\mathrm{Q}_{\mathrm{stCO} 2}$ of PAF-19 and PAF-20 are calculated to be 28.5 and $30.3 \mathrm{~kJ} \cdot \mathrm{mol}^{-1}$ at zero coverage, respectively (Fig. $7 \mathrm{~b}$ ). As expected, PAF-19 and PAF-20 show high $\mathrm{Q}_{\mathrm{stCO} 2}$ owing to their specific networks, which offer a possible arena to enhance their interactions with $\mathrm{CO}_{2}$ molecules. It is worth mentioning that the $\mathrm{Q}_{\mathrm{stCO} 2}$ of PAF-20 is still ranked in a high level among the reported porous materials (Table 1). 


\subsubsection{Liquid sorption}

Liquid sorption is becoming more and more important, especially for the removal of volatile organic compounds. In this respect, the sorption measurements of organic chemical molecules and water in PAF-19 and PAF-20 have been carried out at $298 \mathrm{~K}$ (Fig. 8). From the $\mathrm{H}_{2} \mathrm{O}$ sorption isotherms, PAF-19 and PAF-20 are verified as excellent hydrophobic materials featured by small $\mathrm{H}_{2} \mathrm{O}$ uptakes at $298 \mathrm{~K}$. However, PAF-19 and PAF-20 can adsorb large amounts of methanol and benzene at the same condition. As shown in Fig. 8, steady increases in the uptakes are observed with increasing methanol or benzene vapour pressure for PAF-19 and PAF-20 samples. At the saturated vapour pressure, the sorption of methanol and benzene on PAF-19 and PAF-20 still does not reach the plateau. The adsorbed amounts of methanol and benzene on PAF-19 at $298 \mathrm{~K}$ are $318 \mathrm{mg} \cdot \mathrm{g}^{-1}\left(9.9 \mathrm{mmol} \cdot \mathrm{g}^{-1}\right)$ and $375 \mathrm{mg} \cdot \mathrm{g}^{-1}\left(4.8 \mathrm{mmol} \cdot \mathrm{g}^{-1}\right)$, respectively. Due to the higher BET surface area, there is no doubt that PAF-20 is able to adsorb more methanol and benzene than that of PAF-19 at $298 \mathrm{~K}$, with values of $609 \mathrm{mg} \cdot \mathrm{g}^{-1}\left(19.0 \mathrm{mmol} \cdot \mathrm{g}^{-1}\right)$ and $1038 \mathrm{mg} \cdot \mathrm{g}^{-1}\left(13.3 \mathrm{mmol} \cdot \mathrm{g}^{-1}\right)$, respectively. From another table of liquid sorption list of some porous materials (Table 2), the methanol and benzene sorption abilities of PAF-19 and PAF-20 are higher than those porous materials with similar surface areas, especially for benzene adsorption. This result reveals that there are strong guest-host interactions between benzene molecules and the frameworks of PAF-19 and PAF-20, which could be ascribed to $\pi-\pi$ interactions. The liquid sorption experiments reveal that PAF-19 and PAF-20 are highly hydrophobic materials and featured in a favorable sorption of methanol and benzene compared with $\mathrm{H}_{2} \mathrm{O}$. Such high selectivity towards organic compounds promises PAF-19 and PAF-20 as suitable adsorbents to eliminate harmful organic pollutants from $\mathrm{H}_{2} \mathrm{O}$.

\section{Conclusions}

We present here pyrene-based fluorescent porous aromatic frameworks, PAF-19 and PAF-20, which are constructed by a quadrilateral building unit TBrPy with respective linkers 1,4-diethynylbenzene and 1,3,5-triethynylbenzene via Sonogashira-Hagihara coupling reaction. PAF-19 and PAF-20 possess excellent thermal and chemical stabilities, and comparably high adsorption abilities for hydrogen and carbon dioxide. The plentiful phenyl rings in the polymer networks lead to an enhancement of the adsorption enthalpies for $\mathrm{H}_{2}$ and $\mathrm{CO}_{2}$. Significantly, PAF-19 and PAF-20 are highly hydrophobic materials with high methanol and benzene uptakes at 
the saturated vapour pressure and room temperature. The good performances of PAF-19 and PAF-20 with high sorption selectivity make themselves as ideal candidates in the removal of environmental harmful pollutants from water.

\section{Appendix A. Supplementary data}

Supplementary data associated with this article can be found in the online version.

\section{Acknowledgments}

We are grateful for the financial support of National Basic Research Program of China (973 Program, grant nos. 2012CB821700), Major International (Regional) Joint Research Project of NSFC (grant nos. 21120102034), NSFC (grant nos. 20831002) and Australian Research Council Future Fellowship (FT100101059).

\section{References}

[1] N. B. McKeown, P. M. Budd, Macromolecules 43 (2010) 5163-5176.

[2] J. R. Holst, A. I. Cooper, Adv. Mater. 22 (2010) 5212-5216.

[3] R. Dawson, A. I. Cooper, D. J. Adams, Prog. Polym. Sci. 37 (2012) 530-563.

[4] P. M. Budd, B. S. Ghanem, S. Makhseed, N. B. McKeown, K. J. Msayib, C. E. Tattershall, Chem. Commun. (2004) 230-231.

[5] P. M. Budd, E. S. Elabas, B. S. Ghanem, S. Makhseed, N. B. McKeown, K. J. Msayib, C. E. Tattershall, D. Wang, Adv. Mater. 16 (2004) 456-459.

[6] B. S. Ghanem, N. B. McKeown, P. M. Budd, D. Fritsch, Macromolecules 41 (2008) 1640-1646.

[7] M. Carta, K. J. Msayib, N. B. McKeown, Tetrahedron. Lett. 50 (2009) 5954-5957.

[8] N. B. McKeown, B. Ghanem, K. J. Msayib, P. M. Budd, C. E. Tattershall, K. Mahmood, S. Tan, D. Book, H. W. Langmi, A. Walton, Angew. Chem. Int. Ed. 45 (2006) 1804-1807.

[9] B. Ghanem, N. B. McKeown, K. D. M. Harris, Z. Pan, P. M. Budd, A. Butler, J. Selbie, D. Book, A. Walton, Chem. Commun. (2007) 67-69.

[10] N. Ritter, M. Antonietti, A. Thomas, I. Senkovska, S. Kaskel, J. Weber, Macromolecules 42 (2009) 8017-8020.

[11] B. S. Ghanem, N. B. McKeown, P. M. Budd, N. M. Al-Harbi, D. Fritsch, K. Heinrich, L. Starannikova, A. Tokarev, Y. Yampolskii, Macromolecules 42 (2009) 7881-7888.

[12] J. Weber, M. Antonietti, A. Thomas, Macromolecules 41 (2008) 2880-2885. 
[13] O. K. Farha, A. M. Spokoyny, B. G. Hauser, Y. S. Bae, S. E. Brown, R. Q. Snurr, C. A. Mirkin, J. T. Hupp, Chem. Mater. 21 (2009) 3033-3035.

[14] Z. G. Wang, B. F. Zhang, H. Lu, L. X. Sun, C. L. Jiao, W. S. Liu, Chem. Commun. (2010) $7730-7732$.

[15] O. K. Farha, Y. S. Bae, A. M. Spokoyny, B. G. Hauser, R. Q. Snurr, C. A. Mirkin, J. T. Hupp, Chem. Commun. (2010) 1056-1058.

[16] J. X. Jiang, F. Su, A. Trewin, C. D. Wood, N. L. Campbell, H. Niu, C. Dickinson, A. Y. Ganin, M. J. Rosseinsky, Y. Z. Khimyak, A. I. Cooper, Angew. Chem. Int. Ed. 46 (2007) 8574-8578.

[17] R. Dawson, A. Laybourn, R. Clowes, Y. Z. Khimyak, D. J. Adams, A. I. Cooper, Macromolecules 42 (2009) 8809-8816.

[18] J. X. Jiang, F. Su, H. Niu, C. D. Wood, N. L.Campbell, Y. Z. Khimyak, A. I. Cooper, Chem. Commun. (2008) 486-488.

[19] E. Stockel, X. F. Wu, A. Trewin, C. D. Wood, R. Clowes, N. L. Campbell, J. T. A. Jones, Y. Z. Khimyak, D. J. Adams, A. I. Cooper, Chem. Commun. (2009) 212-214.

[20] R. Dawson, A. Laybourn, Y. Z. Khimyak, D. J. Adams, A. I. Cooper, Macromolecules 43 (2010) $8524-8530$.

[21] J. Jiang, F. Su, A. Trewin, C. D. Wood, N. L. Campbell, H. Niu, C. Dickinson, A. Y. Ganin, M. J. Rosseinsky, Y. Z. Khimyak, A. I. Cooper, J. Am. Chem. Soc. 130 (2008) 7710-7720.

[22] J. Jiang, A. Laybourn, R. Clowes, Y. Z. Khimyak, J. Bacsa, S. J. Higgins, D. J. Adams, A. I. Cooper, Macromolecules 43 (2010) 7577-7582.

[23] L. Chen, Y. Yang, D. Jiang, J. Am. Chem. Soc. 132 (2010) 9138-9143.

[24] J. Weber, A. Thomas, J. Am. Chem. Soc. 130 (2008) 6334-6335.

[25] L. Chen, Y. Hongsho, S. Seki, D. Jiang, J. Am. Chem. Soc. 132 (2010) 6742-6748.

[26] Y. Yuan, F. X. Sun, H. Ren, X. F. Jing, W. Wang, H. P. Ma, H. J. Zhao, G. S. Zhu, J. Mater. Chem. 21 (2011) 13498-13502.

[27] M. Rose, N. Klein, W. Böhlmann, B. Böhringer, S. Fichtner, S. Kaskel, Soft Matter. 6 (2010) 3918-3923.

[28] J. Schmidt, M. Werner, A. Thomas, Macromolecules 42 (2009) 4426-4429.

[29] W. Lu, D. Yuan, D. Zhao, C. Schilling, O. Plietzsch, T. Muller, S. Brase, J. Guenther, J. Blümel, R. Krishna, Z. Li, H.-C. Zhou, Chem. Mater. 22 (2010) 5964-5972. 
[30] J. R. Holst, E. Stöckel, D. J. Adams, A. I. Cooper, Macromolecules 43 (2010) 8531-8538.

[31] A. Trewin, A. I. Cooper, Angew. Chem. Int. Ed. 49 (2010) 1533-1535.

[32] T. Ben, H. Ren, S. Q. Ma, D. P. Cao, J. H. Lan, X. F. Jing, W. C. Wang, J. Xu, F. Deng, J. M. Simmons, S. L. Qiu, G. S. Zhu, Angew. Chem., Int. Ed. 48 (2009) 9457-9460.

[33] H. Ren, T. Ben, F. X. Sun, M. Y. Guo, X. F. Jing, H. P. Ma, K. Cai, S. L. Qiu, G. S. Zhu, J. Mater. Chem. 21 (2011) 10348-10353.

[34] P. Kuhn, M. Antonietti, A. Thomas, Angew. Chem. Int. Ed. 47 (2008) 3450-3453.

[35] P. Kuhn, A. Forget, D. Su, A. Thomas, M. Antonietti, J. Am. Chem. Soc. 130 (2008) $13333-13337$.

[36] P. Kuhn, A. Thomas, M. Antoniietti, Macromolecules 42 (2009) 319-326.

[37] M. J. Bojddys, J. Jeromenok, A. Thomas, M. Antonietti, Adv. Mater. 22 (2010) 2202-2205.

[38] M. J. Bojdys, S. A. Wohlgemuch, A. Thomas, M. Antonietti, Macromolecules 43 (2010) $6639-6645$.

[39] W. Zhang, C. Li, Y. P. Yuan, L. G. Qiu, A. J. Xie, Y. H. Shen, J. F. Zhu, J. Mater. Chem. 20 (2010) 6413-6415.

[40] A. P. Cote, H. M. El-Kaderi, H. Furukawa, J. R. Hunt, O. M. Yaghi, J. Am. Chem. Soc. 129 (2007) 12914-12915.

[41] M. Dogru, A. Sonnauer, A. Gavryushin, P. Knochel, T. Bein, Chem. Commun. (2010) $2462-2464$.

[42] S. Wang, J. Guo, J. Kim, H. Ihee, D. Jiang, Angew. Chem. Int. Ed. 47 (2008) 8826-8829.

[43] R. W. Tilford, S. J. Mugavero, P. J. Pellechia, J. J. Lavigne, Adv. Mater. 20 (2008) 2741-2746.

[44] A. P. Cote, A. I. Benin, N. W. Ockwig, M. O'Keeffe, A. J. Matzger, O. M. Yaghi, Science 310 (2005) 1166-1170.

[45] H. M. El-Kaderi, J. R. Hunt, J. L. Mendoza-Cortes, A. P. Cote, R. E. Taylor, M. O'Keeffe, O. M. Yaghi, Science 316 (2007) 268-272.

[46] F. J. Uribe-Romo, J. R. Hunt, H. Furukawa, C. Klock, M. O'Keeffe, O. M. Yaghi, J. Am. Chem. Soc. 131 (2009) 4570-4571.

[47] H. Furukawa, O. M. Yaghi, J. Am. Chem. Soc. 131 (2009) 8875-8883.

[48] J. Schmidt, J. Weber, J. Epping, M. Antonietti, A. Thomas, Adv. Mater. 21 (2009) 702-705.

[49] S. W.Yuan, S. Kirklin, B. Dorney, D. J. Liu, L. P. Yu, Macromolecules 42 (2009) 1554-1559. 
[50] M. Rose, W. Böhlmann, M. Sabo, S. Kaskel, Chem. Commun. (2008) 2462-2464.

[51] J. Fritsch, M. Rose, P. Wollmann, W. Böhlmann, S. Kaskel, Materials 3 (2010) 2447-2462.

[52] D. S. Zhang, Z. Chang, Y. B. Lv, T. L. Hu, X. H. Bu, RSC Adv. 2 (2012) 408-410.

[53] J. Y. Ying, C. P. Mehnert, M. S. Wong, Angew. Chem., Int. Ed. 38 (1999) 56-77.

[54] Q. H. Hu, S. Z. Qiao, F. Haghseresht, M. A. Wilson, G. Q. Lu, Ind. Eng. Chem. Res. 45 (2006) $733-738$

[55] A. B. Fuertes, G. Marban, D. M. Nevskaia, Carbon 41 (2003) 87-96.

[56] X. Q. Zou, J. E. Fallah, J. M. Goupil, G. S. Zhu, V. Valtchev, S. Mintova, RSC Adv. 2 (2012) $3115-3122$.

[57] C. Venkataramana, S. Sankararaman, Eur. J. Org. Chem. 19 (2005) 4162-4166.

[58] J. X. Jiang, A. Trewin, D. J. Adams, A. I. Cooper, Chem. Sci. 2 (2011) 1777-1781.

[59] K. V. Rao, S. Mohapatra, T. K. Maji, S. J. George, Chem. Eur. J. 18 (2012) 4505-4509.

[60] K. L. Mulfort, T. M. Wilson, M. R. Wasielewski, J. T. Hupp, Langmuir 25 (2009) 503-508.

[61] F. Svec, J. Germain, J. M. J. Frechet, Small 5 (2009) 1098-1111.

[62] T. Ben, C. Y. Pei, D. L. Zhang, J. Xu, F. Deng, X. F. Jinga, S. L. Qiu, Energy Environ. Sci. 4 (2011) 3991-3999.

[63] K. B. Lee, M. G. Beaver, H. S. Caram, S. Sircar, Ind. Eng. Chem. Res. 47 (2008) 8048-8062.

[64] D. Yuan, W. Lu, D. Zhao, H.-C. Zhou, Adv. Mater. 23 (2011) 3723-3725.

[65] C. F. Martin, E. Stöckel, R. Clowes, D. J. Adams, A. I. Cooper, J. J. Pis, F. Rubiera, C. Pevida, J. Mater. Chem. 21 (2011) 5475-5483.

[66] R. Dawson, E. Stöckel, J. R. Holst, D. J. Adams, A. I. Cooper, Energy Environ. Sci. 4 (2011) $4239-4245$.

[67] R. Dawson, D. J. Adams, A. I. Cooper, Chem. Sci. 2 (2011) 1173-1177.

[68] H. Li, M. Eddaoudi, M. O'Keeffe, O. M. Yaghi, Nature 402 (1999) 276-279.

[69] L. Hou, Y. Y. Lin, X. M. Chen, Inorg. Chem. 47 (2008) 1346-1351.

[70] D. X. Xue, Y. Y. Lin, X. N. Cheng, X. M. Chen, Cryst. Growth Des. 7 (2007) 1332-1336.

[71] X. Lin, A. J. Blake, C. Wilson, X. Z. Sun, N. R. Champness, M. W. George, P. Hubberstey, R. Mokaya, M. Schroder, J. Am. Chem. Soc. 128 (2006) 10745-10753.

[72] Y. Peng, T. Ben, J. Xu, M. Xue, X. F. Jing, F. Deng, S. L. Qiu, G. S. Zhu, Dalton Trans. 40 (2011) $2720-2724$. 


\section{Figure Captions:}

Table 1 Summary of surface areas and adsorption enthalpies $\left(\mathrm{Q}_{\mathrm{stH} 2} / \mathrm{Q}_{\mathrm{stCO} 2}\right)$ for PAF-19, PAF-20 and other representative porous materials.

Table 2 Summary of surface areas and liquid vapour sorption $\left(\mathrm{H}_{2} \mathrm{O} /\right.$ methanol/benzene $)$ for PAF-19, PAF-20 and other representative porous materials.

Fig. 1 Schematic illustration for the synthesis of PAF-19 (a) and PAF-20 (b).

Fig. 2 FTIR spectra of PAF-19 (a, black) and PAF-20 (b, black) polymer networks, and their respective starting materials, 1,3,6,8-tetrabromopyrene (red), 1,4-diethynylbenzene (blue), and 1,3,5-triethynylbenzene (green) in the range of $400-4000 \mathrm{~cm}^{-1}$.

Fig. 3 HRTEM images of PAF-19 (a, b) and PAF-20 (c, d) samples.

Fig. 4 TGA plots for PAF-19 (black) and PAF-20 (red) polymer networks in air condition with a heating rate of $5{ }^{\circ} \mathrm{C} \mathrm{min}^{-1}$.

Fig. 5 Nitrogen adsorption (filled symbols)-desorption (empty symbols) isotherms for PAF-19 (a) and PAF-20 (b). The insets show the pore size distribution derived from $\mathrm{N}_{2}$ adsorption calculated by the NL-DFT method.

Fig. 6 (a) Hydrogen adsorption (filled symbols) and desorption (empty symbols) isotherms of PAF-19 (black circle at $77 \mathrm{~K}$, black triangle at $87 \mathrm{~K}$ ), and PAF-20 (red circle at $77 \mathrm{~K}$, red triangle at $87 \mathrm{~K}$ ); (b) isosteric heats of adsorption of PAF-19 (black) and PAF-20 (red) for hydrogen.

Fig. 7 (a) Carbon dioxide adsorption (filled symbols) and desorption (empty symbols) isotherms of PAF-19 (black circle at $273 \mathrm{~K}$, black triangle at $298 \mathrm{~K}$ ), and PAF-20 (red circle at $273 \mathrm{~K}$, red triangle at $298 \mathrm{~K}$ ); (b) isosteric heats of adsorption of PAF-19 (black) and PAF-20 (red) for carbon dioxide.

Fig. 8 Water (black), methanol (blue) and benzene (red) adsorption isotherms at 298 K for PAF-19 (a) and PAF-20 (b). 
Table 1 Summary of surface areas and adsorption enthalpies $\left(\mathrm{Q}_{\mathrm{stH} 2} / \mathrm{Qst}_{\mathrm{CO} 2}\right)$ for PAF-19, PAF-20 and other representative porous materials.

\begin{tabular}{|c|c|c|c|c|c|c|}
\hline Material & $\begin{array}{c}\mathrm{S}_{\mathrm{BET}} \\
\left(\mathrm{m}^{2} \cdot \mathrm{g}^{-1}\right)\end{array}$ & $\begin{array}{c}\mathrm{H}_{2} \text { uptake } \\
\text { (wt } \%)\end{array}$ & $\begin{array}{c}\mathrm{Q}_{\mathrm{stH} 2} \\
\left(\mathrm{~kJ} \cdot \mathrm{mol}^{-1}\right)\end{array}$ & $\begin{array}{c}\mathrm{CO}_{2} \text { uptake } \\
(\mathrm{mmol} / \mathrm{g})\end{array}$ & $\begin{array}{c}\mathrm{Q}_{\mathrm{stCO} 2} \\
\left(\mathrm{~kJ} \cdot \mathrm{mol}^{-1}\right)\end{array}$ & Ref \\
\hline PAF-1 & 5600 & $1.66^{a}$ & 5.4 & $2.05^{f}$ & 15.6 & [62] \\
\hline PAF-3 & 2932 & $2.07^{a}$ & 6.6 & $3.48^{f}$ & 19.2 & [62] \\
\hline PAF-4 & 2246 & $1.50^{a}$ & 6.3 & $2.41^{f}$ & 16.2 & [62] \\
\hline PAF-19 & 250 & $0.55^{a}$ & 6.99 & $0.90^{e}$ & 28.5 & This work \\
\hline PAF-20 & 702 & $0.89^{a}$ & 8.07 & $1.16^{e}$ & 30.3 & This work \\
\hline COF-1 & 750 & $1.46^{b}$ & 6.2 & & & {$[47]$} \\
\hline COF-5 & 1670 & $3.54^{b}$ & 6.0 & & & [47] \\
\hline COF-6 & 750 & $2.23^{b}$ & 7.0 & & & [47] \\
\hline COF-8 & 1350 & $3.46^{b}$ & 6.3 & & & [47] \\
\hline COF-10 & 1760 & $3.88^{b}$ & 6.6 & & & [47] \\
\hline COF-102 & 3620 & $7.16^{b}$ & 3.9 & & & [47] \\
\hline COF-103 & 3530 & $6.98^{b}$ & 4.4 & & & [47] \\
\hline PPN-1 & 1249 & $1.37^{a}$ & 7.59 & $11^{g}$ & $\sim 27.5$ & [29] \\
\hline PPN-2 & 1764 & $1.51^{a}$ & 6.89 & $19^{g}$ & $\sim 22.5$ & [29] \\
\hline PPN-3 & 2840 & $1.58^{a}$ & 5.51 & $25.3^{g}$ & $\sim 18.6$ & [29] \\
\hline PPN-4 & 6461 & $8.34^{c}$ & 4.0 & & & [64] \\
\hline HCP 1 & 1646 & & & $3.01^{e}$ & 23.5 & [65] \\
\hline HCP 2 & 1684 & & & $3.30^{e}$ & 21.2 & [65] \\
\hline HCP 3 & 1531 & & & $3.24^{e}$ & 22.1 & [65] \\
\hline $\mathrm{HCP} 4$ & 1642 & & & $3.92^{e}$ & 21.6 & [65] \\
\hline MOP A & 4077 & & & $2.65^{e}$ & $\sim 24.0$ & [66] \\
\hline MOP B & 1847 & & & $3.29^{e}$ & $\sim 22.0$ & [66] \\
\hline MOP C & 1237 & & & $3.86^{e}$ & $\sim 34.0$ & [66] \\
\hline MOP D & 1213 & & & $2.42^{e}$ & $\sim 26.5$ & [66] \\
\hline MOP E & 1470 & & & $2.95^{e}$ & $\sim 25.5$ & [66] \\
\hline MOP F & 653 & & & $1.80^{e}$ & $\sim 27.0$ & [66] \\
\hline MOP G & 1056 & & & $2.15^{e}$ & $\sim 26.8$ & [66] \\
\hline CMP-1 & 837 & $1.14^{d}$ & $\sim 10.0$ & $2.05^{e}$ & $\sim 27.0$ & {$[21,67]$} \\
\hline CMP-1-(OH $)_{2}$ & 1043 & & & $1.80^{e}$ & $\sim 27.6$ & {$[67]$} \\
\hline CMP-1-( $\left(\mathrm{CH}_{3}\right)_{2}$ & 899 & & & $1.64^{e}$ & $\sim 26.8$ & [67] \\
\hline CMP-1-NH ${ }_{2}$ & 710 & & & $1.64^{e}$ & $\sim 29.5$ & {$[67]$} \\
\hline CMP-1-COOH & 522 & & & $1.60^{e}$ & 32.6 & [67] \\
\hline BPL carbon & 1250 & $1.52^{b}$ & 8.0 & $2.09^{e}$ & 24.3 & {$[47,63]$} \\
\hline
\end{tabular}


Table 2 Summary of surface areas and liquid vapour sorption $\left(\mathrm{H}_{2} \mathrm{O} /\right.$ methanol/benzene) for PAF-19, PAF-20 and other representative porous materials.

\begin{tabular}{lccrrrr}
\hline Material & $\begin{array}{c}\mathrm{S}_{\mathrm{BET}} \\
\left(\mathrm{m}^{2} \cdot \mathrm{g}^{-1}\right)\end{array}$ & $\begin{array}{c}\mathrm{H}_{2} \mathrm{O} \\
\left(\mathrm{mg} \cdot \mathrm{g}^{-1}\right)\end{array}$ & $\begin{array}{c}\text { Methanol } \\
\left(\mathrm{mg} \cdot \mathrm{g}^{-1}\right)\end{array}$ & $\begin{array}{c}\text { Benzene } \\
\left(\mathrm{mg} \cdot \mathrm{g}^{-1}\right)\end{array}$ & $\begin{array}{c}\mathrm{T} \\
(\mathrm{K})\end{array}$ & Ref \\
MOF-5 & $2900^{a}$ & & & 802 & 295 & {$[68]$} \\
$\mathrm{PAF}-5$ & 1503 & & 934 & 917 & 298 & {$[33]$} \\
{$\left[\mathrm{Zn}{ }_{4} \mathrm{O}(\mathrm{bdc})(\mathrm{bpz})_{2}\right] \cdot 4 \mathrm{DMF} \cdot 6 \mathrm{H}_{2} \mathrm{O}$} & 1476 & & $\sim 500^{c}$ & $\sim 620^{c}$ & 298 & {$[69]$} \\
$\mathrm{PAF}-11$ & 704 & 35 & 654 & 874 & 298 & {$[26]$} \\
$\mathrm{PAF}-20$ & 702 & 65 & 609 & 1038 & 298 & $b$ \\
{$\left[\mathrm{Cu}_{2}(\mathrm{bdc})_{2}(\mathrm{dmf}) \mathrm{H}_{2} \mathrm{O} \cdot(\mathrm{dmf})\left(\mathrm{C}_{2} \mathrm{H}_{5} \mathrm{OH}\right)_{0.5}\right.$} & 374 & & $\sim 170^{c}$ & $\sim 70^{c}$ & 298 & {$[70]$} \\
{$\left[\mathrm{Zn}_{2}(\mathrm{~L})\right]_{\infty}$} & 313 & 154 & 84 & 90 & 298 & {$[71]$} \\
$\mathrm{JUC}_{\infty}-\mathrm{Z1}$ & 283 & $\sim 22$ & & 273 & 298 & {$[72]$} \\
$\mathrm{PAF}-19$ & 250 & 26 & 318 & 375 & 298 & $b$ \\
&
\end{tabular}



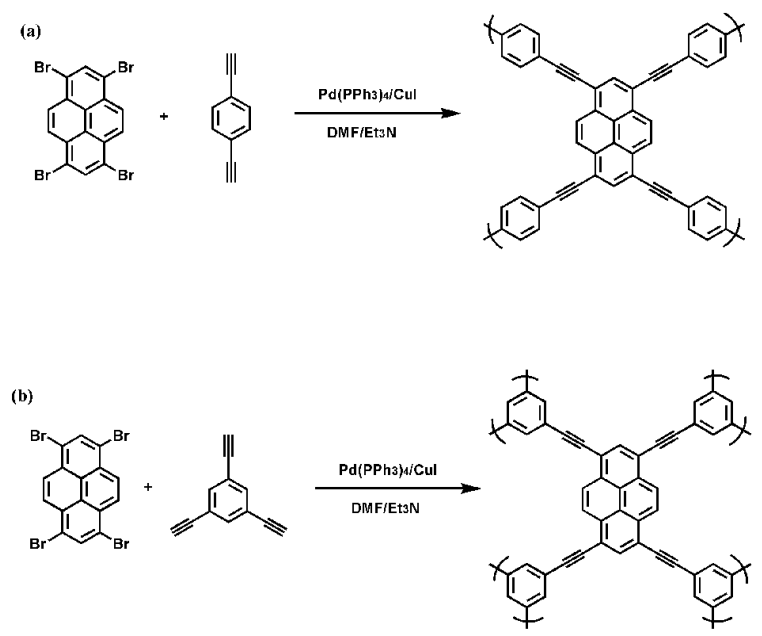

Fig. 1 Schematic illustration for the synthesis of PAF-19 (a) and PAF-20 (b). 

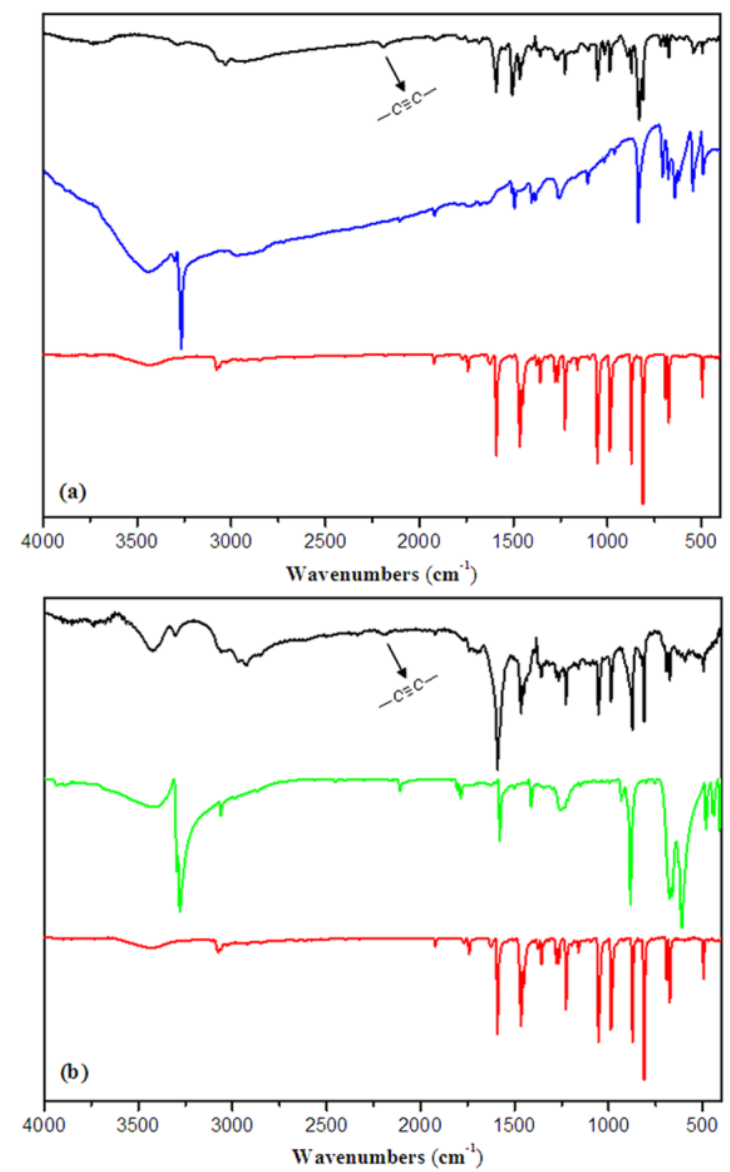

Fig. 2 FTIR spectra of PAF-19 (a, black) and PAF-20 (b, black) polymer networks, and their respective starting materials, 1,3,6,8-tetrabromopyrene (red), 1,4-diethynylbenzene (blue), and 1,3,5-triethynylbenzene (green) in the range of $400-4000 \mathrm{~cm}^{-1}$. 


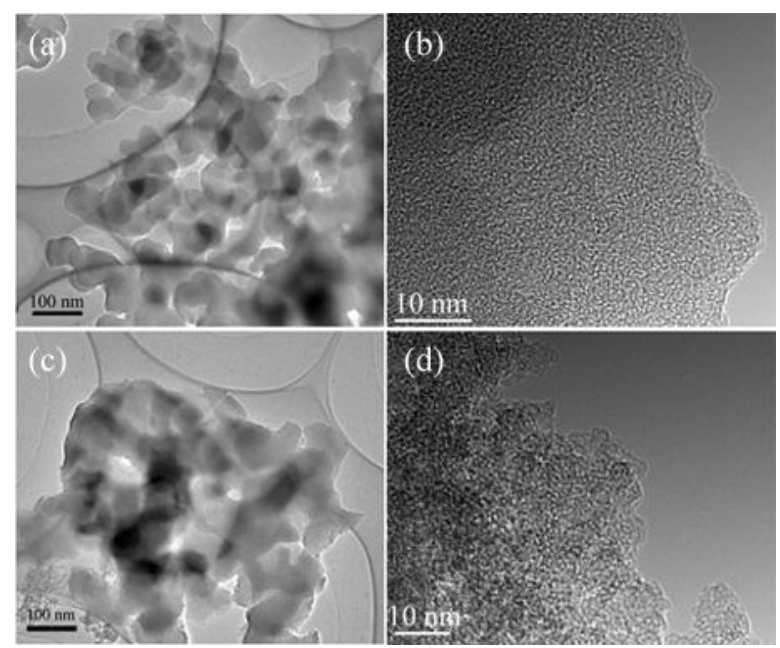

Fig. 3 HRTEM images of PAF-19 (a, b) and PAF-20 (c, d) samples. 


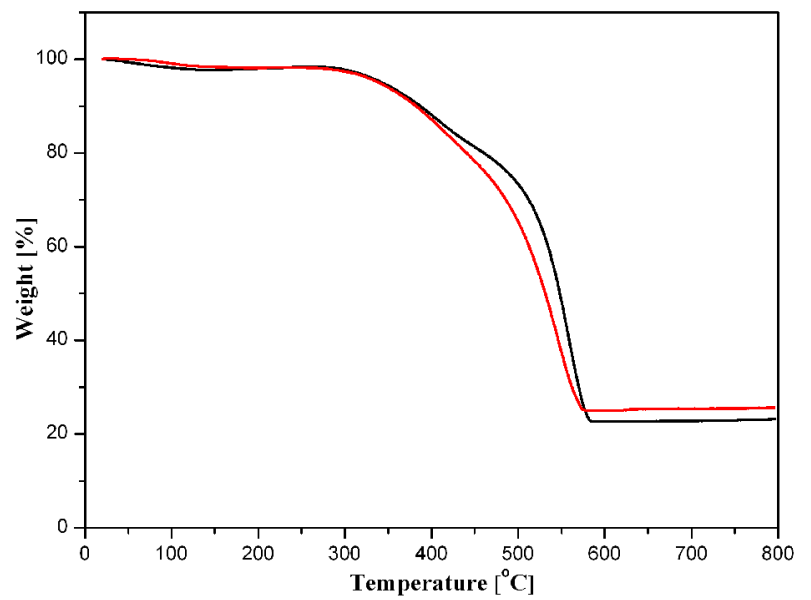

Fig. 4 TGA plots for PAF-19 (black) and PAF-20 (red) polymer networks in air condition with a heating rate of $5{ }^{\circ} \mathrm{C} \mathrm{min}^{-1}$. 

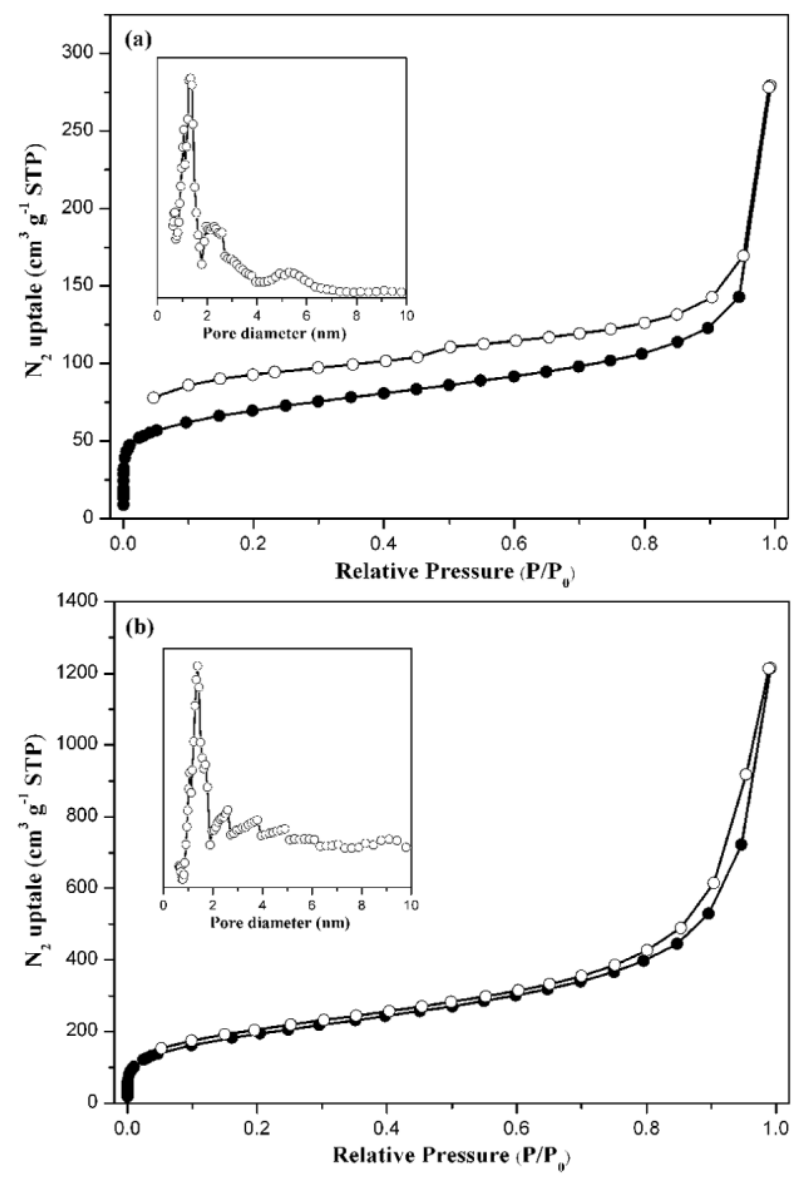

Fig. 5 Nitrogen adsorption (filled symbols)-desorption (empty symbols) isotherms for PAF-19 (a) and PAF-20 (b). The insets show the pore size distribution derived from $\mathrm{N}_{2}$ adsorption calculated by the NL-DFT method. 

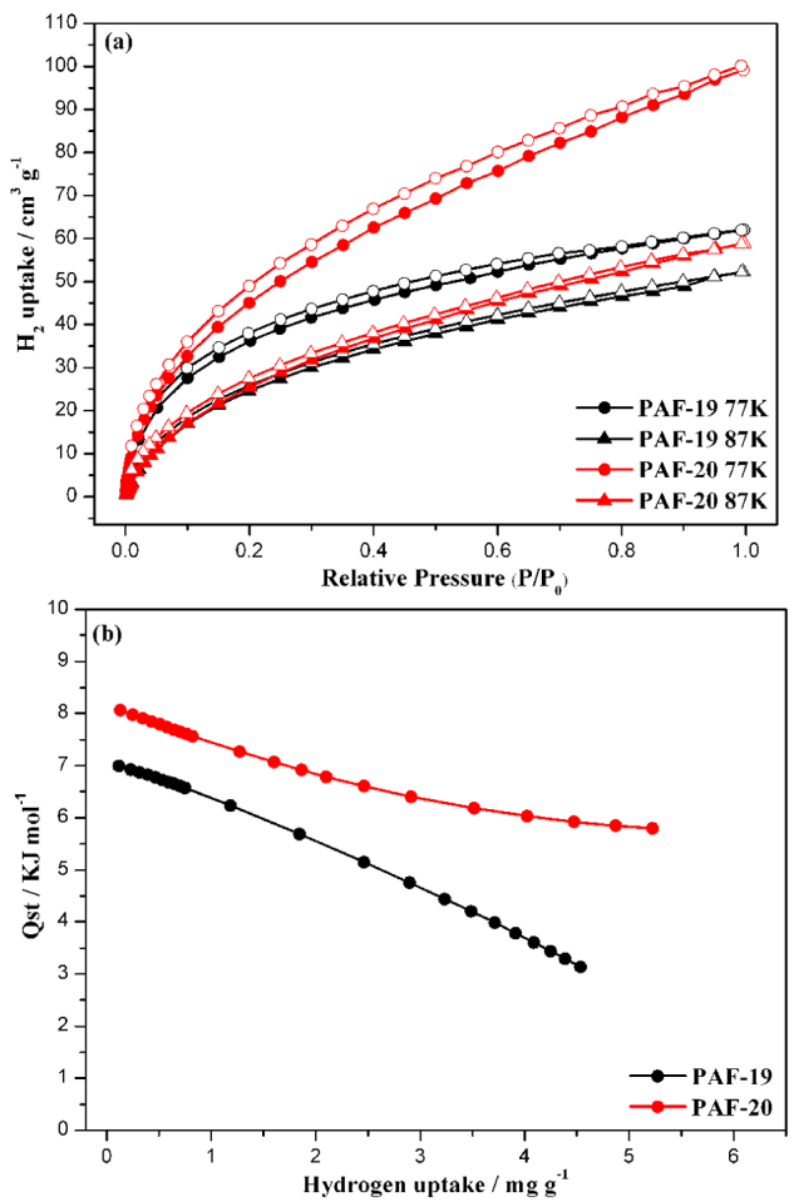

Fig. 6 (a) Hydrogen adsorption (filled symbols) and desorption (empty symbols) isotherms of PAF-19 (black circle at $77 \mathrm{~K}$, black triangle at $87 \mathrm{~K}$ ), and PAF-20 (red circle at $77 \mathrm{~K}$, red triangle at $87 \mathrm{~K}$ ); (b) isosteric heats of adsorption of PAF-19 (black) and PAF-20 (red) for hydrogen. 

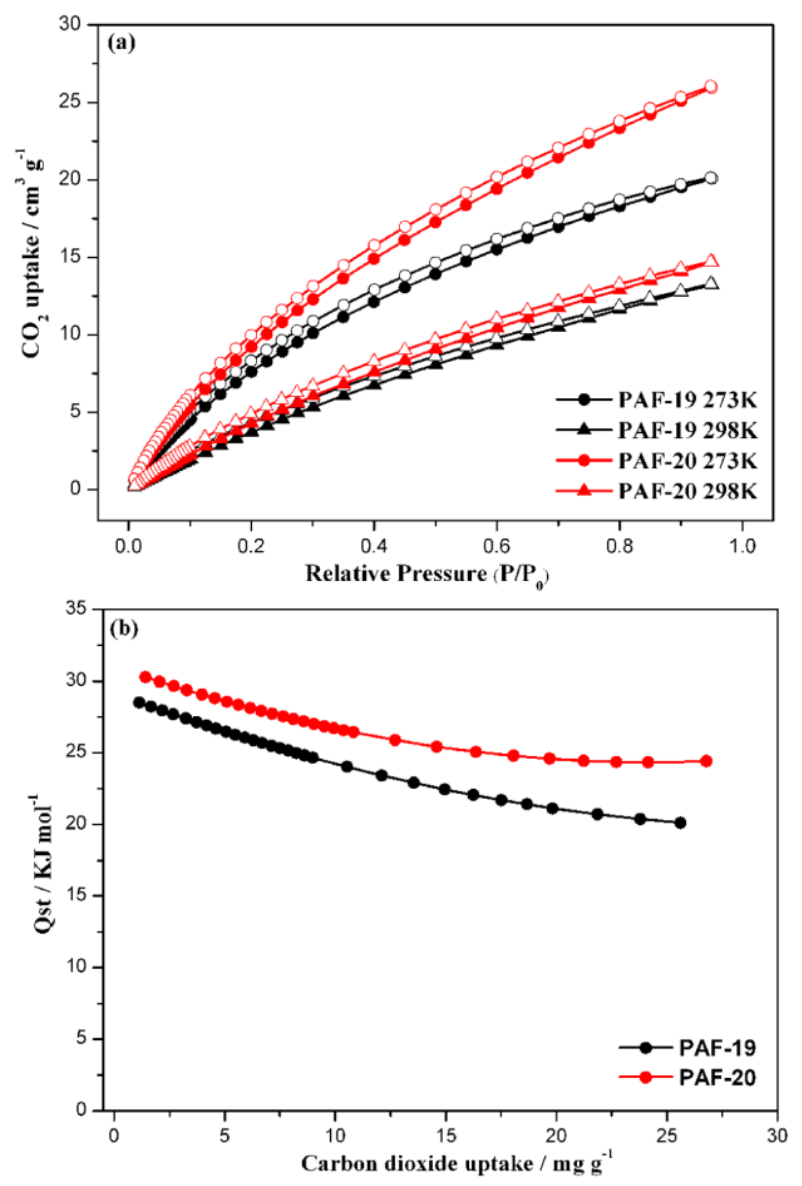

Fig. 7 (a) Carbon dioxide adsorption (filled symbols) and desorption (empty symbols) isotherms of PAF-19 (black circle at $273 \mathrm{~K}$, black triangle at $298 \mathrm{~K}$ ), and PAF-20 (red circle at $273 \mathrm{~K}$, red triangle at $298 \mathrm{~K}$ ); (b) isosteric heats of adsorption of PAF-19 (black) and PAF-20 (red) for carbon dioxide. 

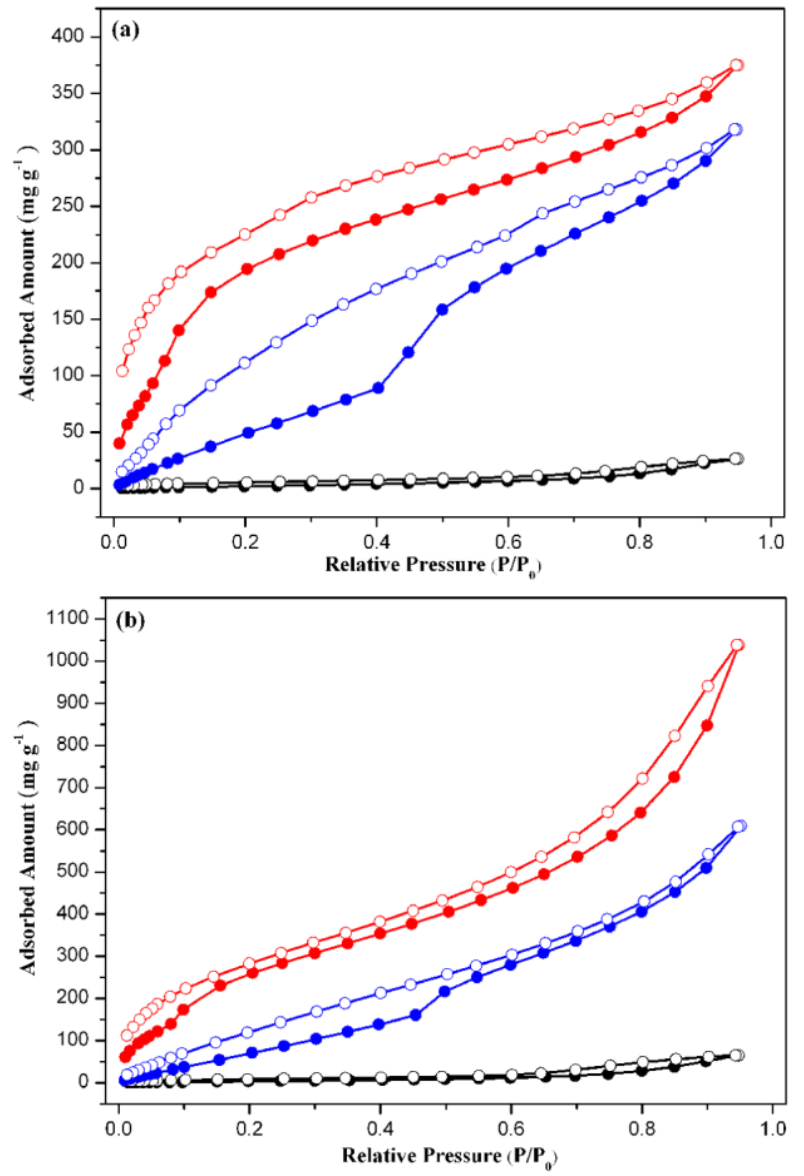

Fig. 8 Water (black), methanol (blue) and benzene (red) adsorption isotherms at 298 K for PAF-19 (a) and PAF-20 (b). 


\section{Graphical abstract}
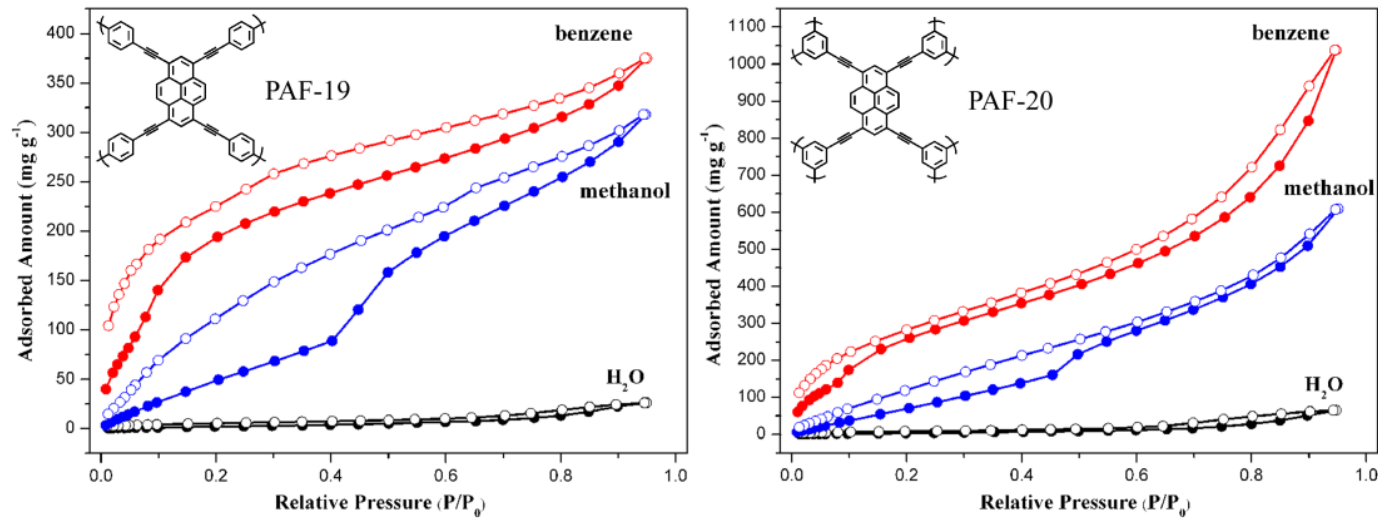

Targeted synthesis of pyrene-based porous aromatic frameworks has been achieved via Sonogashira-Hagihara coupling reaction. PAF-19 and PAF-20 are highly hydrophobic materials with high methanol and benzene uptakes at the saturated vapour pressure and room temperature.

\section{Highlights}

Pyrene-based porous aromatic frameworks are synthesized via Sonogashira-Hagihara coupling reaction.

The plentiful phenyl rings in the networks lead to an enhancement for the adsorption enthalpies of $\mathrm{H}_{2}$ and $\mathrm{CO}_{2}$.

Materials with hydrophobic skeletons for highly selective sorption of benzene and methanol. 